\title{
The relationship between birth weight and insulin resistance in childhood
}

\author{
Jesuana O. Lemos ${ }^{1}$, Patricia H. C. Rondó ${ }^{1 *}$, Joilane A. Pereira ${ }^{1}$, Renata G. Oliveira ${ }^{1}$, Maria B. S. Freire ${ }^{2}$ \\ and Patricia B. Sonsin ${ }^{1}$ \\ ${ }^{1}$ Department of Nutrition, School of Public Health, University of São Paulo, Avenida Dr Arnaldo 715, São Paulo, SP, \\ CEP-01246-904, Brazil \\ ${ }^{2} J u n d i a i ́$ Medical School, Rua Francisco Telles, 250, Vila Arens, Jundiaí, SP, CEP-13202-550, Brazil \\ (Received 7 November 2008 - Revised 3 July 2009 - Accepted 7 August 2009 - First published online 22 September 2009)
}

Chronic diseases that are typical of adulthood may originate in intra-uterine life through inadequate fetal development. The present epidemiological cohort study of 506 healthy children aged 5-8 years evaluated the relationship between birth weight and insulin resistance in an age group that has been assessed in few similar studies. Insulin concentration was determined by chemiluminescence and insulin resistance by the homeostasis model assessment (HOMA). Blood glucose, total cholesterol and fractions (LDL cholesterol and HDL cholesterol) and TAG concentrations were determined by automated enzymatic methods. Linear regression analysis investigated the relationship between birth weight (assessed as a continuous variable and in three categories: small for gestational age, SGA; adequate for gestational age and large for gestational age) and the HOMA index, using backward stepwise selection and biological models to explain the causal pathway of the relationship. There were negative associations between birth weight $(P<0.001)$, SGA $(P=0.027)$ and the HOMA index, and a positive association between waist circumference $(P<0 \cdot 001)$ and the HOMA index. Considering the significant associations between birth weight and waist circumference $(P<0 \cdot 001)$ and waist circumference and insulin resistance $(P<0.001)$, we can probably suspect that lower birth weight is a common cause of higher waist circumference and insulin resistance. In summary, the results of the present study showed increased insulin resistance in apparently healthy, young children, who had lower weight at birth and higher measurements of waist circumference. There is a need to develop public health policies that adopt preventive measures to promote adequate maternal-fetal and child development and enable early diagnosis of metabolic abnormalities.

Birth weight: Insulin resistance: Waist circumference: Dyslipidaemia: Children

The prevalence of chronic-degenerative diseases is related to the presence of obesity, excess energy, fat and salt intake and reduced physical activity, which are elements of the so-called nutritional transition ${ }^{(1)}$. However, it has been demonstrated that diseases that are typical of adulthood may originate during intra-uterine life through inadequate fetal development ${ }^{(2-9)}$. According to the gestational phase during which intra-uterine growth restriction occurs, different systems will be affected, predisposing to diabetes mellitus type 2 , arterial hypertension, obesity and dyslipidaemia ${ }^{(10-13)}$.

The theory known as the 'Fetal origins of disease' or the 'Thrifty phenotype hypothesis' suggests that individuals who are exposed to nutritional deficiency in the uterus and during the first years of life adapt themselves to this deficiency. In relation to the pancreas, the adaptation mechanism consists of decreases in the number and activity of $\beta$-cells and harm to insulin-dependent tissues, especially muscles. Therefore, to survive during periods of nutritional deprivation, fetuses change their metabolic-endocrine routes and become insulin resistant. If, over the course of life, individuals with lower weights at birth are subjected to situations of increased food intake and decreased physical activity, this adaptation may become evident, thereby predisposing towards reduced insulin resistance, obesity and diabetes mellitus type $2^{(6,11,14,15)}$.

In Brazil, as in other developing countries like India, the prevalence of chronic-degenerative diseases including metabolic diseases is increasing, representing an important cause of death even in young adults ${ }^{(16,17)}$.

The present study investigated the relationship between birth weight and insulin resistance in a cohort of 506 Brazilian children aged 5-8 years, involving an age group that has been assessed in few similar studies ${ }^{(18-24)}$.

\section{Materials and methods}

This is an epidemiological cohort study initially involving 865 children who were followed up from birth until 5-8 years of age $^{(25)}$. The children were born to women who took part in a cohort study in Jundiaí city, Brazil, between 1997 and 2000. The women attended antenatal care in twelve health units and five hospitals in Jundiaí city, and were followed before the 16th week of pregnancy to the birth of their babies. All participants were insured by the National Health Service

Abbreviations: HDL-c, HDL cholesterol; HOMA, homeostasis model assessment; LBW, low birth weight; LDL-c, LDL cholesterol; SGA, small for gestational age. * Corresponding author: Dr Patricia H. C. Rondó, fax +55 113061 7771, email phcrondo@usp.br 
(SUS) that assists low-income families. Women with chronic infectious diseases, metabolic diseases, cardiopathy, mental diseases, hypertension/pre-eclampsia/eclampsia, vaginal bleeding and multiple deliveries were not included in the study. The children were classified after birth as being small for gestational age (SGA), adequate for gestational age and large for gestational age ${ }^{(26)}$. Details of the study are given elsewhere ${ }^{(27)}$.

Out of the 865 mother-infant pairs from the previous cohort $^{(27)}, 745$ were located and invited to participate in the present study, resulting in a final sample of 649 children, whose parents signed a free and informed consent statement and answered a general questionnaire.

The study was carried out between November 2004 and September 2006 and consisted of two phases. (1) Taking the information from the questionnaire of the first cohort study into account, the mothers who at that time were living in the city of Jundiaí and nearby municipalities were located. The mothers were invited to participate in the present study through telephone contact or by visiting their homes if they did not have a telephone. Next, a home visit was made, during which the objectives of the study were explained, and the ethical consent statement was signed by the child's parents or guardians. At the time of this home visit, a general questionnaire was applied in order to evaluate socio-economic and demographic data and any morbidity among the children. (2) The participants were contacted again by telephone to arrange to collect anthropometric data (weight, height and waist circumference) and blood samples in order to determine glucose, total cholesterol, HDL cholesterol (HDL-c), LDL cholesterol (LDL-c) and TAG concentrations.

The anthropometric data were obtained in accordance with the recommendations of Cameron ${ }^{(28)}$ and Jelliffe \& Jelliffe ${ }^{(29)}$. The children were weighed, after been fasting for $10-12 \mathrm{~h}$, by a portable electronic scale (Sohnle ${ }^{\circledR}$, model 7500, Murrhardt, Germany), with accuracy of $100 \mathrm{~g}$. Their height was measured using a SECA ${ }^{\circledR}$ stadiometer (Leicester Portable Height measure model, Hamburg, Germany), with accuracy of $0.1 \mathrm{~cm}$. The waist circumference measurements were obtained using a tape measure (Stanley ${ }^{\circledR}$, model 34103 , New Britain, CT, USA) of accuracy $0 \cdot 1 \mathrm{~cm}$. The BMI was classified according to the Centers for Disease Control and Prevention $^{(30)}$ and International Obesity Task Force classifications $^{(31)}$. Mean values of waist circumference were compared with a British standard ${ }^{(32)}$.

Immediately after collection of the blood samples for determination of the glucose and insulin concentrations and the lipid profile, the material was centrifuged at $1500 \mathrm{rpm}$ for $10 \mathrm{~min}$ (Tomy centrifuge, model IC-15AN, Tominaga Works Ltd, Tokyo, Japan) and then stored in a refrigerator at $0^{\circ} \mathrm{C}$ for a period of $24-48 \mathrm{~h}$, for the biochemical tests' determinations.

Glucose was obtained by an enzymatic method using the Bayer ${ }^{\circledR}$ ADVIA 1200 clinical chemistry system (Pittsburgh, PA, USA) for glucose hexokinase. Fasting glycaemia concentration was based on the criteria currently adopted for diagnosing diabetes mellitus type 2 and was the same for adults and children ${ }^{(33)}$. Insulin was assayed in serum by a chemiluminescence method using the Immulite 2000 apparatus (Immulite ${ }^{\circledR}$, DPC, Los Angeles, CA, USA). To determine insulin resistance, the homeostasis model assessment (HOMA) method was used ${ }^{(34)}$ by the formula: HOMA $=$ fasting glucose $(\mathrm{mmol} / \mathrm{l}) \times$ fasting insulin $(\mu \mathrm{U} / \mathrm{ml}) / 22 \cdot 5$. Insulin resistance was considered to be present when HOMA was $\geq 2 \cdot 5^{(8,35)}$.

Assays for total cholesterol and HDL-c were performed by a colorimetric enzymatic method, using the Bayer ${ }^{\circledR}$ ADVIA 1200 clinical chemistry system. The concentrations of LDL-c were determined by the Friedwald ${ }^{(36)}$ formula. TAG concentrations were determined photometrically following an enzymatic reaction using the Bayer ${ }^{\circledR}$ ADVIA 1200 clinical chemistry system. Total cholesterol and fractions and TAG concentrations were classified in accordance with the recommendations of the First Guidelines for the Prevention of Atherosclerosis during Childhood and Adolescence ${ }^{(37)}$.

The categorical variables were analysed by the $\chi^{2}$ test with Yates correction, applying the Fisher's exact test when the frequency was less than five. The Student's $t$ test or the Mann-Whitney test was used to compare mean values of pairs of independent variables. The relationship between birth weight and the HOMA index, and the variables of interest were determined using Pearson's or Spearman's correlation. The impact of birth weight and other independent variables (selected according to their importance, correlation coefficient and biological collinearity) on the HOMA index was determined by multiple linear regression, using the backward stepwise selection method. The outcome HOMA index - was analysed separately for each independent variable. The variables with descriptive level of $P \leq 0.20$ (birth weight, age, sex, BMI, waist circumference, HDL-c, LDL-c, TAG and per capita income) were selected for entry into the multiple linear regression model.

In addition to the use of birth weight as a continuous variable, a second linear multiple regression model tested the association between birth weight by gestational age

Table 1. Characteristics of the children at birth

(Mean values and standard deviations)

\begin{tabular}{lrrrr}
\hline Variables & $n$ & \multicolumn{1}{c}{$\%$} & Mean & SD \\
\hline GA (weeks) & 18 & $3 \cdot 67$ & $39 \cdot 16$ & 1.32 \\
$\quad<37$ & 468 & $95 \cdot 51$ & & \\
$37-42$ & 4 & $0 \cdot 82$ & \\
$\quad \geq 42$ & 490 & $100 \cdot 00$ & \\
Total & & & \\
Sex & 239 & $46 \cdot 4$ & \\
Male & 267 & $53 \cdot 6$ & \\
Female & 506 & $100 \cdot 00$ & \\
Total & & & \\
Birth weight (g) & 29 & 5.73 & \\
$\quad<2500$ & 128 & $25 \cdot 30$ & \\
2500-2999 & 214 & $42 \cdot 29$ & \\
3000-3499 & 111 & 21.94 & \\
3500-3999 & 24 & 4.74 & \\
$\geq 4000$ & 506 & $100 \cdot 00$ & \\
Total & & & \\
Weight for GA & & & \\
Small for GA & 63 & 12.4 & \\
Adequate for GA & 423 & $83 \cdot 1$ & \\
Large for GA & 23 & 4.5 & \\
Total & 506 & $100 \cdot 00$ & \\
\hline
\end{tabular}

GA, gestational age. 
(in three categories: SGA, adequate for gestational age and large for gestational age) and HOMA, controlling for the variables cited above. Moreover, biological models were investigated in order to explain the causal pathway of the relationship between birth weight and insulin resistance.

In the final models, the variables with a $P \leq 0.05$ were considered as being statistically significant. The software Epi Info 6.04 (Atlanta, GA, USA) and Stata version 9 (College Station, TX, USA) were used for data storage and for statistical analysis.

The present study was carried out in accordance with the Declaration of Helsinki of the World Medical Association, and it was approved by the Research Ethics Committee of the School of Public Health, University of São Paulo.

\section{Results}

The biochemical parameters were determined in the second phase of the study involving a total of 506 children. There was a loss of $32 \%$ children, considering all the mothers who were located ( $n 745$ mothers) in the first phase of the study, and a loss of $41.5 \%$ children, considering the mothers who participated in the original cohort ( $n 865$ mothers).

There was a significant difference between the mean age of the children included in the cohort (6.5 (SD 0.7) years) and the children who did not conclude the study (5.9 (SD $0 \cdot 8$ ) years; $P=0 \cdot 01$ ). However, there was no difference in relation to per capita income, birth weight or mother's schooling level. The characteristics of the children at birth are presented in Table 1. With regard to gestational age, $95.5 \%$ were born at term ( $\geq 37$ and $<42$ weeks of gestation) and $53.6 \%$ were female.

Table 2 shows that most of the children (53.4\%) were between 6 and 7 years old. Approximately, $67.0 \%$ of the participants had a per capita income of less than one Brazilian minimum monthly salary (one Brazilian minimum monthly salary = approximately US\$ 77). According to the Centers for Disease Control and Prevention BMI classification ${ }^{(30)}$, $45(8.9 \%)$ of the children were underweight, $346(68.6 \%)$ were normal, $72(14.3 \%)$ were at risk of becoming overweight and $41(8.2 \%)$ were overweight. Sixty-six children (twenty-one males and forty-five females) (12.9\%) were overweight, and twenty-seven children (twelve males and fifteen females; $5.3 \%$ ) were obese by the International Obesity Task Force classification ${ }^{(31)}$. The percentages were lower to studies involving Mexican and British children with comparable ages ${ }^{(38,39)}$. Mean waist circumferences of the children were higher than the 75 th percentile of a British standard ${ }^{(32)}$. High fasting glycaemia (5.6-6.9 mmol/1 (700-1000 mg/l)) was observed in sixty-one children $(12.0 \%)$ and nineteen (3.7\%) presented an abnormal HOMA index $(\geq 2.5 \mathrm{mmol} / 1$ $\mu \mathrm{U} / \mathrm{ml})$. Total cholesterol was high $(\geq 4.4 \mathrm{mmol} / \mathrm{l} ; 1700 \mathrm{mg} / \mathrm{l})^{(37)}$ in 168 children $(33.2 \%)$. One hundred and two children $(20.2 \%)$ presented HDL-c that was lower than recommended $(1.2 \mathrm{mmol} / \mathrm{l} ; 450 \mathrm{mg} / \mathrm{l})$ and twenty-two $(4.3 \%)$ were in the group of children with abnormal LDL-c $(\geq 3.4 \mathrm{mmol} / \mathrm{l}$; $1300 \mathrm{mg} / \mathrm{l})$.

Table 3 shows the correlations between birth weight, gestational age, demographic, socio-economic, anthropometric and biochemical factors. Birth weight was significantly correlated with all the anthropometric parameters investigated.
Table 2. Socio-demographic, nutritional and biochemical characteristics of the children

(Mean values and standard deviations)

\begin{tabular}{|c|c|c|c|c|}
\hline Variables & $n$ & $\%$ & Mean & SD \\
\hline Age (years) & & & $6 \cdot 57$ & 0.66 \\
\hline $5-6$ & 101 & 19.9 & & \\
\hline $6-7$ & 270 & 53.4 & & \\
\hline $7-8$ & 135 & $26 \cdot 7$ & & \\
\hline Per capita income (BMMS) & & & 0.94 & 0.77 \\
\hline$<1.00$ & 340 & 67.5 & & \\
\hline $1.00-2 \cdot 00$ & 130 & $25 \cdot 8$ & & \\
\hline $3 \cdot 00-7 \cdot 14$ & 34 & $6 \cdot 7$ & & \\
\hline $\mathrm{BMI}^{(30)}$ & & & $15 \cdot 94$ & $2 \cdot 33$ \\
\hline Underweight ( $<5$ th percentile) & 45 & 8.9 & & \\
\hline Normal weight (5-85th percentile) & 346 & $68 \cdot 6$ & & \\
\hline $\begin{array}{l}\text { Risk of overweight (85-95th } \\
\text { percentile) }\end{array}$ & 72 & $14 \cdot 3$ & & \\
\hline Overweight ( $\geq 95$ th percentile) & 41 & $8 \cdot 2$ & & \\
\hline Waist circumference ${ }^{(32)}$ & & & 56.54 & 6.53 \\
\hline Boys in all ages ( $>75$ th percentile) & 239 & 47 & & \\
\hline Girls $<7$ years ( $>90$ th percentile) & 192 & 38 & & \\
\hline$\geq 7$ years $(>75$ th percentile) & 75 & 15 & & \\
\hline Glucose $(\mathrm{mmol} / \mathrm{l})$ & & & $5 \cdot 2$ & 0.4 \\
\hline$<3.9$ & 3 & 0.6 & & \\
\hline $3.9-5.6$ & 442 & $87 \cdot 4$ & & \\
\hline $5 \cdot 6-6 \cdot 9$ & 61 & $12 \cdot 0$ & & \\
\hline $\operatorname{HOMA}(\mathrm{mmol} / \mathrm{l})(\mu \mathrm{U} / \mathrm{ml})$ & & & 1.00 & 0.80 \\
\hline$<2.5$ & 487 & $96 \cdot 3$ & & \\
\hline$\geq 2.5$ & 19 & 3.7 & & \\
\hline Total cholesterol $(\mathrm{mmol} / \mathrm{l})$ & & & $4 \cdot 1$ & 0.8 \\
\hline$<3.9$ & 208 & $41 \cdot 1$ & & \\
\hline $3.9-4.4$ & 130 & $25 \cdot 7$ & & \\
\hline$\geq 4.4$ & 168 & $33 \cdot 2$ & & \\
\hline HDL-c (mmol/l) & & & 1.4 & 0.3 \\
\hline$<1.2$ & 102 & $20 \cdot 2$ & & \\
\hline$\geq 1 \cdot 2$ & 404 & $89 \cdot 8$ & & \\
\hline LDL-c (mmol/l) & & & $2 \cdot 3$ & $0 \cdot 7$ \\
\hline$<2 \cdot 6$ & 358 & $70 \cdot 8$ & & \\
\hline $2 \cdot 6-3 \cdot 4$ & 126 & 24.9 & & \\
\hline$\geq 3.4$ & 22 & $4 \cdot 3$ & & \\
\hline TAG (mmol/l) & & & $0 \cdot 8$ & 0.4 \\
\hline$<1.1$ & 424 & 83.8 & & \\
\hline $1 \cdot 1-1 \cdot 5$ & 62 & $12 \cdot 2$ & & \\
\hline$\geq 1.5$ & 20 & $4 \cdot 0$ & & \\
\hline
\end{tabular}

BMMS, Brazilian minimum monthly salary $(\mathrm{R} \$ 350.00=$ approximately US $\$ 77$ per capita income); HOMA, homeostasis model assessment; HDL-c, HDL cholesterol; LDL-c, LDL cholesterol.

Table 4 presents multiple linear regression models taking the HOMA index as the dependent variable and birth weight (considered as a continuous variable and categorised by gestational age as SGA, adequate for gestational age and large for gestational age) as the independent variable. In the first and second models, a backward stepwise selection method was utilised, controlling for the following variables: age; sex; BMI; waist circumference; HDL-c; LDL-c; TAG; per capita income. In the first model, the HOMA index was negatively associated with birth weight $(P<0 \cdot 001)$ and positively associated with waist circumference $(P<0 \cdot 001)$. In the second model, the HOMA index was positively associated with SGA $(P=0.027)$ and waist circumference $(P<0.001)$.

There was a positive association between birth weight and waist circumference $(P<0 \cdot 001)$, but no interaction between the two variables $(P>0.05)$. In a univariate linear regression analysis, birth weight did not present a statistically significant association with the HOMA index $(P=0 \cdot 06$; Table 3$)$. 
Table 3. Correlation coefficients between birth weight (BW) and the variables of interest

\begin{tabular}{llc}
\hline Variables & BW & $P$ \\
\hline BW & 1.000 & \\
GA & 0.452 & $<0.001$ \\
Weight & 0.249 & $<0.001$ \\
Height & 0.219 & $<0.001$ \\
BMI & 0.194 & $<0.001$ \\
WC & 0.188 & $<0.001$ \\
TC & 0.044 & 0.61 \\
HDL & 0.014 & 0.86 \\
LDL & 0.043 & 0.57 \\
TAG & 0.008 & 0.95 \\
Glucose & -0.009 & 0.91 \\
Insulin & -0.089 & 0.06 \\
HOMA & -0.092 & 0.06 \\
Age & -0.010 & 0.81 \\
Income & 0.042 & 0.13 \\
\hline
\end{tabular}

GA, gestational age; WC, waist circumference; TC, total cholesterol; HOMA, homeostasis model assessment; Income, per capita income.

All the variables were assessed in childhood, with the exception of BW and GA.

Tu et al. ${ }^{(40)}$ reported that an inference regarding the existence and direction of an association between birth weight and an outcome occurring later in life depends on whether one adjusts or does not adjust for current weight in setting up the regression model. Therefore, based on $\mathrm{Tu}$ et al. ${ }^{(40)}$ study, and trying to investigate biological models, we carried out a regression analysis assessing the association between birth weight and the HOMA index adjusting the model for body weight and also for BMI. There were statistically significant associations between birth weight, weight in childhood and the HOMA index, and birth weight, BMI in childhood and the HOMA index (third and fourth models in Table 4). The first model described in Table 4 was also adjusted for weight and BMI in childhood (fifth and sixth models in
Table 4); the associations between the HOMA index, birth weight and waist circumference remained significant.

\section{Discussion}

The children assessed in this cohort presented a considerable prevalence of low $(<2500 \mathrm{~g})$, deficient or insufficient (2500-2999 g) weight (Table 1); a factor of concern with regard to their potential growth and development and risk of morbidity-mortality ${ }^{(41)}$.

According to the multiple linear regression analysis utilised in the present study, birth weight (as a continuous variable and categorised as SGA) and insulin resistance, assessed by the HOMA index, were associated. A reduction of $100 \mathrm{~g}$ in birth weight resulted in an increase of $0.026 \mathrm{mmol} / \mathrm{l} \mu \mathrm{U} / \mathrm{ml}$ in the HOMA index. The mean value of HOMA for these children was 1.0 ( $\mathrm{SD}=0.8$; Table 2). Possibly, the increase in the HOMA index can have a clinical significance for the children. According to a large review on validation of the HOMA index, the parameter has an appropriate use in cohort and epidemiological studies for assessing insulin resistance $^{(42)}$

Yajnig et al. ${ }^{(18)}$ reported an association between insulin resistance and birth weight in 4-year-old Indian children. Four years later, his group of researchers studied the same children ( $n$ 477) and found out that the lower birth weight was associated with increased HOMA, and that the highest levels of insulin resistance syndrome variables and total and LDL cholesterol were in children of low birth weight (LBW) but high fat mass at 8 years ${ }^{(19)}$. Wilkin et al. ${ }^{(20)}$ and Jeffery et al. ${ }^{(21)}$ reported, in the EarlyBird study, correlations between insulin resistance and weight in approximately 300 children at 5 and 8 years of age, but none with birth weight. The Pune Maternal Nutrition Study ${ }^{(24)}$ assessed the associations of size and body proportions at birth, and

Table 4. Linear regression models considering insulin resistance (homeostasis model assessment, HOMA) as outcome

\begin{tabular}{|c|c|c|c|c|}
\hline \multicolumn{5}{|c|}{ Insulin resistance (HOMA)* } \\
\hline First model & Coefficient & SE & $95 \% \mathrm{Cl}$ & $P$ \\
\hline Birth weight (g) & $-0.26 \times 10^{-3}$ & $0.69 \times 10^{-3}$ & $-0.39 \times 10^{-3}, 0.12 \times 10^{-3}$ & $<0.001$ \\
\hline Waist circumference (cm) & 0.049 & 0.005 & $0.039,0.059$ & $<0.001$ \\
\hline \multicolumn{5}{|l|}{ Second model } \\
\hline SGA & 0.2256 & 0.1020 & $0.0252,0.4260$ & 0.027 \\
\hline LGA & -0.1033 & 0.1611 & $-0.4200,0.2133$ & 0.522 \\
\hline Waist circumference (cm) & 0.041 & 0.0049 & $0.0316,0.0510$ & $<0.001$ \\
\hline \multicolumn{5}{|l|}{ Third model } \\
\hline Birth weight (g) & $-0.29 \times 10^{-3}$ & $0.73 \times 10^{-4}$ & $-0.43 \times 10^{-3},-0.15 \times 10^{-3}$ & $<0.001$ \\
\hline Weight $(\mathrm{kg})$ & 0.052 & $0.65 \times 10^{-2}$ & $0.039-0.065$ & $<0.001$ \\
\hline \multicolumn{5}{|l|}{ Fourth model } \\
\hline Birth weight (g) & $-0.26 \times 10^{-3}$ & $0.71 \times 10^{-4}$ & $-0.40 \times 10^{-3},-0.12 \times 10^{-3}$ & $<0.001$ \\
\hline BMI & $0 \cdot 116$ & 0.014 & $0.09,0.14$ & $<0.001$ \\
\hline \multicolumn{5}{|l|}{ Fifth model } \\
\hline Birth weight (g) & $-0.26 \times 10^{-3}$ & $0.72 \times 10^{-4}$ & $-0.41 \times 10^{-3},-0.12 \times 10^{-3}$ & $<0.001$ \\
\hline Waist circumference (cm) & 0.040 & 0.011 & $0.018,0.063$ & $<0.001$ \\
\hline Weight (kg) & 0.004 & 0.015 & $-0.025,0.034$ & 0.761 \\
\hline \multicolumn{5}{|l|}{ Sixth model } \\
\hline Birth weight $(\mathrm{g})$ & $-0.27 \times 10^{-3}$ & $0.71 \times 10^{-4}$ & $-0.41 \times 10^{-3},-0.13 \times 10^{-3}$ & $<0.001$ \\
\hline Waist circumference (cm) & 0.030 & 0.011 & $0.93 \times 10^{-2}-5.15 \times 10^{-2}$ & 0.005 \\
\hline $\mathrm{BMI}$ & $4.11 \times 10^{-2}$ & $2.98 \times 10^{-2}$ & $-1.74 \times 10^{-2}, 9.97 \times 10^{-2}$ & 0.168 \\
\hline
\end{tabular}

SGA, small for gestational age; LGA, large for gestational age.

${ }^{*}$ First model: $R^{2}$ adjusted $=0.16$; second model: $R^{2}$ adjusted $=0.12$; third model: $R^{2}$ adjusted $=0.11$; fourth model: $R^{2}$ adjusted $=0 \cdot 12$; fifth model: $R^{2}$ adjusted $=0 \cdot 13$; sixth model: $R^{2}$ adjusted $=0.14$ 
growth during infancy and childhood, to body composition and CVD risk factors (insulin resistance, blood pressure, glucose tolerance and plasma lipids) in 698 children at the age of 6 years. The authors reported that smaller mid-upper arm circumference at 6 months predicted higher insulin resistance $(P<0.001)$, but larger mid-upper arm circumference at 1 year predicted higher systolic blood pressure $(P<0.001)$. Gupta et al. ${ }^{(23)}$ reported an association between insulin resistance and birth weight in 134 Indian children and adolescents from 5 to 16 years of age, controlling for waist circumference, waist:hip ratio, age, sex and BMI. Giapros et al. ${ }^{(22)}$ observed that large for gestational age-born children aged $6 \cdot 5-8$ years had higher HOMA and adiponectin concentration than adequate for gestational age children.

The possible explanations for the association between birth weight and insulin resistance are the following: (a) most of the development of the pancreatic islets occurs in the uterus and, in human subjects, the mass of $\beta$-cells increases more than 130 -fold between the 12th week of gestation and the 5 th month after birth ${ }^{(44)}$. Studies on animals have shown that nutritional deprivation within the uterus or just after birth may reduce the number of $\beta$-cells and the secretion of insulin, while noting that protein concentrations are directly related to the production of $\beta$-cells by the pancreas ${ }^{(45)}$. In addition to lower insulin production, it can also be considered that LBW is related to glucose intolerance ${ }^{(46)}$; (b) under unfavourable conditions of intra-uterine nutrition, there is a reduction in the proportion of lean mass relative to body fat. This pattern favours insulin resistance as a mean of adaptation ${ }^{(47)}$. These abnormalities would cause structural changes that could persist into adulthood. The main strategy for fetal adaptation to deficient nutrition is selective redistribution of nutrients for the formation of fundamental organs like the brain (brain sparing). This mechanism would result in underdevelopment of the skeleton and liver, a lower proportion of muscle mass, diminished mass of $\beta$-cells from the pancreas and abnormalities in vascular tissues ${ }^{(48,49)}$. A study carried out in South Africa ${ }^{(50)}$ involving 132 young adults indicates that the 'fetal origins' expression of the chronic disease phenotype is not dependent on birth weight alone, but on its interaction with subsequent fat accumulation, including measurements of waist circumference.

The present study also shows a positive association between waist circumference and the HOMA index. Mean waist circumferences of the children involved in the study were higher than mean waist circumference measurements of British children at the same age ${ }^{(32)}$. However, there were not many overweight or obese children, according to the Centers for Disease Control and Prevention or International Obesity Task Force classifications. The same phenomenon has been observed in Asia: central obesity even in the absence of obesity ${ }^{(51)}$. Molist-Brunet et al. ${ }^{(47)}$ observed that as waist circumference increased the risk that insulin resistance would occur was higher. Yajnik ${ }^{(51)}$, involving 8-year-old children, also found a relationship between HOMA, insulin, waist circumference and birth weight. A study carried out on the Caribbean island of Barbados showed an association between LBW girls with a family history of diabetes and higher HOMA. LBW girls without a family history of diabetes had a smaller waist circumference than normal birth weight girls. In contrast, LBW girls with a family history of diabetes had similar mean waist circumference than normal birth weight girls with a family history of diabetes ${ }^{(52)}$.

As stated by Barker ${ }^{(15)}$, the explanation for the accumulation of centrally located fat is that, during intra-uterine life, energy saving may occur in order to maintain brain development and functioning. These savings would generate a positive energy balance that, in adulthood, would cause an accumulation of fat, especially in the central region of the body. This centralisation of adiposity is related to insulin resistance and lower development of muscle mass, and it consists of a substrate enabling metabolic speed in providing glucose through stress-related metabolic pathways, with the aim of maintaining adequate glucose levels, particularly in the brain ${ }^{(53)}$

The fetal origins hypothesis, as related to insulin resistance, affirms the existence of a causal path from prenatal factors to insulin resistance. From the public health viewpoint, we want to know whether interventions undertaken in pregnancy might be of benefit to the health of the offspring later in life.

According to the present results, it is difficult to conclude that waist circumference is a potential pathway between birth weight and insulin resistance. Waist circumference in childhood may be influenced not only by birth weight ${ }^{(15)}$, but probably by prenatal factors acting through effects on fetal growth (as measured by birth weight) ${ }^{(54)}$ and factors occurring in childhood. Poor prenatal nutrition, for example, may act as a common cause of lower birth weight and higher waist circumference, determining insulin resistance.

Despite the non-significant result of the association between birth weight and the HOMA index (in the univariate linear regression analysis), a $P$-value of 0.06 has probably a biological value, considering the number of factors that could intervene in the association throughout prenatal life to childhood. However, if we consider that this association is not statistically significant, and that the associations between birth weight and waist circumference and waist circumference and insulin resistance are significant, we can probably suspect, according to Hernán et al. ${ }^{(55)}$, that lower birth weight is a common cause of higher waist circumference and insulin resistance.

Weinberg ${ }^{(56)}$ asserted that aetiological inferences cannot be trusted to a regression package and that decisions about confounding and when to adjust can have a qualitative impact on our conclusions. According to the author, while we often cannot construct a complete causal pathway, we can gain important guidance from the attempt, clarify the assumptions we are making and then focus on those epidemiologic questions that are answerable.

Epidemiological studies have been conducted over the last decades in an attempt to determine the relationship between birth weight and outcomes in later life, most of them retrospective studies involving adult populations. Few prospective studies have been carried out on children ${ }^{(18-24)}$. To our knowledge, there is no Brazilian cohort study investigating the association between birth weight and metabolic abnormalities in this age group.

In conclusion, the results of the present study showed increased insulin resistance in apparently healthy, young children, who had lower weight at birth and higher measurements of waist circumference. There is a need to carry out 
large cohort epidemiological studies assessing several factors throughout pregnancy and childhood to a better understanding of the causal pathway between prenatal factors and insulin resistance. Some questions that now are quite difficult to answer in terms of causal pathways will probably be better understood, and help to develop public health policies that adopt preventive measures to promote adequate maternalfetal and child development and enable early diagnosis of metabolic abnormalities.

\section{Acknowledgements}

The authors gratefully acknowledge Fundação de Amparo à Pesquisa do Estado de São Paulo (FAPESP; Grant No. 04/ 04 109-8), for financing the present study, Prof. José Maria P. Souza, and the field workers Alessandra L. Santos, Rosemary F. Ferreira and Josimara F. Moura. There are no conflicts of interest to declare.

J. O. L. collected data, participated in the statistical analysis and interpretation of data, and writing of the paper. P. H. C. R. designed the study protocol, secured funding, facilitated data collection, participated in the statistical analysis and interpretation of data, and writing of the paper. J. A. P. collected data, participated in the statistical analysis and interpretation of data, and writing of the paper. R. G. O. participated in data collection, statistical analysis and writing of the paper. M. B. S. F. participated in the statistical analysis, interpretation of data and writing of the paper. P. B. S. participated in the statistical analysis, interpretation of data and writing of the paper.

\section{References}

1. Yajnik CS (2000) Interactions of perturbations in intrauterine growth during childhood on the risk of adult-onset disease. Proc Nutr Soc 59, 257-265.

2. De Blasio MJ, Gatford KL, McMillen IC, et al. (2007) Placental restriction of fetal growth increases insulin action, growth, and adiposity in the young lamb. Endocrinology 148, 1350-1358.

3. Barker DJ (2007) The origins of the developmental origins theory. J Intern Med 261, 412-417.

4. Barker DJ (2005) The developmental origins of insulin resistance. Horm Res 64, Suppl. 3, 2-7.

5. de Boo HA \& Harding JE (2006) The developmental origins of adult disease (Barker) hypothesis. Aust N Z J Obstet Gynaecol 46, 4-14.

6. Eriksson JG, Forsén T, Tuomilehto J, et al. (2002) Effects of size at birth and childhood growth on the insulin resistance syndrome in elderly individuals. Diabetologia 45, 342-348.

7. Tanaka Y, Kikuchi T, Nagasaki K, et al. (2005) Lower birth and visceral fat accumulation are related to hyperinsulinemia and insulin resistance in obese Japanese children. Hypertens Res 28, 529-536.

8. Valerio G, Licenziati MR, Iannuzzi A, et al. (2006) Insulin reistance and impaired glucose tolerance in obese children and adolescents from Southern Italy. Nutr Metab Cardiovasc Dis 16, 279-284.

9. Mi J, Cheng H, Zhao XY, et al. (2008) Developmental origin of metabolic syndrome: interaction of thinness at birth and overweight during adult life in Chinese population. Obes Rev 9 Suppl. 1, 91-94.

10. Barker DJP (2007) Obesity and early life. Obesity 8, Suppl. 1, 45-49.
11. Yudkin JS (2007) Insulin resistance and the metabolic syndrome - or the pitfalls of epidemiology. Diabetologia $\mathbf{5 0}$, $1576-1586$.

12. Law CM (2002) Significance of birthweight for the future. Arch Dis Child Fetal Neonatal 86, 7-8.

13. Yajnik CS (2004) Early life origins of insulin resistance and type 2 diabetes in India and other Asian Countries. $J$ Nutr 134, 205-210.

14. Yajnik CS \& Deshmukh US (2008) Maternal nutrition, intrauterine programming and consequential risks in the offspring. Rev Endocr Metab Disord 9, 203-211.

15. Barker DJP, Winter PD, Osmmond C, et al. (1989) Weight in infancy and death from ischaemic heart disease. Lancet 334, 577-580.

16. Ramachandran A, Snehalatha C, Latha E, et al. (1997) Rising prevalence of NIDDM in an urban population in India. Diabetologia 40, 232-237.

17. Ministério da Saúde (2004) Evolução da Mortalidade no Brasil (The Evolution of Mortality in Brazil). Vigilância em Saúde, MS: Ministério da Saúde.

18. Yajnik CS, Fall CHD, Vaydia U, et al. (1995) Fetal growth and glucose and insulin metabolism in four year old Indian children. Diabet Med 12, 330-336.

19. Bavdekar A, Yajnik CS, Fall CHD, et al. (1999) Insulin resistance syndrome in 8-year old Indian children. Small at birth, big at 8 years, or both? Diabetes 48, 2422-2429.

20. Wilkin TJ, Voss LD, Metcalf BS, et al. (2004) Metabolic risk in early childhood: The EarlyBird Study. Int J Obes Relat Metab Disord 28, Suppl. 3, S64-S69.

21. Jeffery AN, Metcalf BS, Hosking J, et al. (2006) Little evidence for early programming of weight and insulin resistance for contemporary children: EarlyBird Diabetes Study report 19. Pediatrics 118, 1118-1123.

22. Giapros V, Evagelidou E, Challa A, et al. (2007) Serum adiponectin and leptin levels and insulin resistance in children born large for gestational age are affected by the degree of overweight. Clin Endocrinol 66, 353-359.

23. Gupta M, Gupta R, Pareek A, et al. (2007) Low birth weight and insulin resistance in mid and late childhood. Indian Pediatr $\mathbf{4 4}$ $177-184$.

24. Joglekar CV, Fall CH, Deshpande VU, et al. (2007) Newborn size, infant and childhood growth, and body composition and cardiovascular disease risk factors at the age of 6 years: The Pune Maternal Nutrition Study. Int $J$ Obes 31, $1534-1544$.

25. Rondó PHC, Lemos JO, Pereira JA, et al. (2008) Relationship between birth weight and arterial elasticity in childhood. Clin Sci 115, 317-326.

26. Williams RL, Creasy RK, Cunningham MD, et al. (1982) Fetal growth and perinatal viability in California. Obstet Gynecol 59, 624-632.

27. Rondó PHC, Ferreira RF, Nogueira F, et al. (2003) Maternal psychological stress and distress as predictors of low birth weight, prematurity and intra- uterine growth retardation. Eur J Clin Nutr 57, 266-272.

28. Cameron N (1984) The Measurement of Human Growth, 1st ed. London: Croom Helm.

29. Jelliffe DB \& Jelliffe EFP (1989) Community Nutritional Assessment, With Special Reference to Less Technically Developed Countries, 2nd ed. London: Oxford University Press.

30. CDC - Centers for Disease Control and Prevention \& National Center for Health Statistics (2000) CDC, United States of America. http://www.cdc.gov/growthcharts

31. Cole TJ, Bellizzi MC, Flegal KM, et al. (2000) Establishing a standard definition for child overweight and obesity worldwide: international survey. BMJ 320, 1240-1243. 
32. McCarthy HD, Jarrett KV \& Crawley HF (2001) The development of waist circumference percentiles in British children aged 5.0-16.9 y. Eur J Clin Nutr 55, 901-907.

33. American Diabetes Association Position Statement (2004) Diagnosis and classification of diabetes mellitus. Diabetes Care 27, Suppl. 1, 5-10.

34. Matthews DR, Hosker JP, Rudenski AS, et al. (1985) Homeostasis model assessment: insulin resistance and beta cel function from fasting plasma glucose and insulin concentrations in man. Diabetologia 28, 412-419.

35. D'Annunzio G, Vanelli M, Meschi F, et al. (2004) The SIEDP Study Group. Valori normali di- HOMA-IR in bambini e adolescents: studio multicentrico italiano. Quad Pediatr 3, 44.

36. Friedwald WT, Levy RI \& Fredrickson DS (1972) Estimation of the concentration of low-density lipoprotein cholesterol in plasma, without use of the preparative ultra centrifuge. Clin Chem 18, 499-502.

37. Giuliano ICB, Caramelli B, Pellanda L, et al. (2006) I Guideline for preventing atherosclerosis in childhood and adolescence. Int $J$ Atheroscler 1, 1-30.

38. Moraes AS, Beltran RJ, Mondini L, et al. (2006) Prevalence of overweight and obesity, and associated factors in school children from urban area in Chilpancingo, Guerrero, Mexico, 2004. Cad Saude Publica 22, 1289-1301.

39. Jebb SA, Rennie KL \& Cole TJ (2004) Prevalence of overweight and obesity among young people in Great Britain. J Public Health Nutr 7, 461-465.

40. Tu YK, West R, Ellison GTH, et al. (2005) Why evidence for the fetal origins of adult disease might be a statistical artifact: the 'reversal paradox' for the relation between birth and blood pressure in later life. Am J Epidemiol 161, 27-32.

41. Wallace TM, Levy JC \& Matthews DR (2004) Use and abuse of HOMA modeling. Diabetes Care 27, 1487-1495.

42. Fowden AL (1985) Pancreatic endocrinology function and carbohydrate metabolism in the fetus. In Perinatal Endocrinology, vol. IV, pp. 71-90 [E Albrecht and GJ Pepe, editors]. Ithaca, NY: Perinatology Press.

43. Snoeck A, Remacle C, Reusens B, et al. (1990) Effect of a low protein diet during pregnancy on the fetal rat endocrine pancreas. Biol Neonate 57, 107-118.
44. Yajnik CS (2002) The lifecycle effects of nutrition and body size on adult adiposity, diabetes and cardiovascular disease. Obes Res 3, 217-224.

45. Hovi P, Anderson S, Eriksson JG, et al. (2007) Glucose regulation in young adults with very low birth weight. $N \mathrm{Engl}$ $J$ Med 358, 2053-2063.

46. Krentz AJ (2002) Insulin Resistance: A Clinical Handbook, 1st ed. Oxford: Blackwell Science.

47. Molist-Brunet N, Jimeno-Mollet J \& Franch-Nadal J (2006) Correlation between the various measurements of obesity and the degree of resistance to insulin. Aten Primaria 37, 30-36.

48. Yajnik CS, Godbole K \& Lubree H (2007) Fetal programming of type 2 diabetes: is sex important? Diabetes Care 30, $2754-2755$

49. Levitt NS, Lambert EV, Woods D, et al. (2005) Adult BMI and fat distribution but not height amplify the effect of low birth weight on insulin resistance and increased blood pressure in 20-year-old South Africans. Diabetologia 48, $1118-1125$.

50. McKeigue PM, Shah B \& Marmot MG (1991) Relation of central obesity and insulin resistance with diabetes prevalence and cardiovascular risk in South Asians. Lancet 337, 382-386.

51. Yajnik CS (2003) Nutrition, growth, and body size in relation to insulin resistance and type 2 diabetes. Curr Diab Rep 3, $108-114$.

52. Chambers EC, Tull ES, Fraser H, et al. (2005) A family history of diabetes is related to abnormal insulin sensitivity in AfricanCaribbean girls of low birth weight: is catch-up weight important? Ethn Dis 15, 424-428.

53. Bjorntorp P (1993) Visceral obesity: a 'civilization syndrome'. Obes Res 1, 206-222.

54. Li L, Manor O \& Power C (2004) Early environment and childto-adult growth trajectories in the 1958 British birth cohort. Am $J$ Clin Nutr 80, 185-192.

55. Hernán MA, Hernández-Díaz S, Werler M, et al. (2002) Causal knowledge as a prerequisite for confounding evaluation: an application to birth defects epidemiology. Am J Epidemiol 155, 176-184.

56. Weinberg RC (2005) Invited Commentary: Barker meets Simpson. Am J Epidemiol 161, 33-35. 